\title{
Towards the Effectiveness of a Co-evolutionary Framework in Information Systems Organizations
}

\author{
Muhammad Asif Khan*, Essa Abdullah Hezzam \\ College of Computer Science and Engineering, Taibah University, Madina al Munawwara, Saudi Arabia. \\ * Corresponding author. Email: asifkhan2k@yahoo.com \\ Manuscript submitted March 8, 2016; accepted July 25, 2016.
}

doi: $10.17706 /$ jcp.12.6.521-526

\begin{abstract}
Information technology (IT) has become an increasingly essential part of business organizations. Many organizations invest in IT but return on investment is not achieved as anticipated before the investment. It is considered that business may grow provided the underlying technologies completely support the business processes. In other words if business and IT co-evolve organizations could achieve the objectives of the business. In the present study we have reviewed and used a co-evolutionary framework to determine its effectiveness in different information systems (IS) organizations in Saudi Arabia. The framework has been implemented in few organizations and data has been collected from different levels in the organizations. The data and results have been presented that show how alignment between business and IT has been achieved in the organizations.
\end{abstract}

Key words: Co-evolution, business-IT gap, alignment.

\section{Introduction}

Today information technology (IT) has become an essential part of organizations in order to expedite business processes. But despite of heavy investment in IT to become a competitive in marketplace many organizations are unable to achieve their targets. The literature shows may reasons in organizations for not being able to be competitive the main concern is alignment between business and IT [1]. Since IT supports business processes it is important that IT strategy is developed with business strategy. In other words both IT and business strategies should co-evolve in order to have a great impact on business processes and achieve business objectives. A framework has been developed that is useful in co-evolution of business and IT and helps reducing gap found in business-IT alignment ([2]. Organizations function in a dynamic environment where business needs, services and products constantly change to meet customer requirements. In order to meet customer demands and due to dynamic nature of business most of the organizations do not update underpinning technologies and hence there occurs a misalignment between business and IT.

In this paper an empirical study of a co-evolutionary framework that has been implemented in different IS organizations in order to determine its effectiveness. Also factors that may cause gap between business and information technology have been investigated in this study. The intent of this study is to contribute to the body of knowledge that could be used by practitioners, researchers and enterprise managers to know impacts of business-IT strategies in organizations.

\section{Literature Review}


IT has changed the operations of businesses and the way organizations are competing consequently enterprises are investing heavily in IT to becoming more competitive in marketplace. Most of the organizations invest capital without knowing the existing alignment between business and IT. An alignment is the situation in which organization's existing and emerging business strategy is enabled, supported, and unrestricted by technology [3]. An alignment is the degree to which organization's objectives are missions of business strategy are supported by IT mission, objectives and strategy [4]. The alignment between business and IT perturbs when business strategy is not supported by technology or vice versa. Strategy is a plan and set of activities and tactics that are adopted by enterprises in order to get a competitive advantage in marketplace. When business managers plan business strategies IT people are not given due consideration consequently business strategies are not supported by IT properly and as a result misalignment occurs. Therefore, it is important that IT is used strategically in such a manner that both business and IT strategies are aligned. For business-IT alignment a conceptual model-driven approach is presented with the aim to restrict of freedom in process modeling [5]. A strategy is a visionary plan that details out techniques and activities for long period of time in order to gain a position in a marketplace and achieve organizational goals. Organizations develop business and IT strategies and aligning both the strategies results in achieving success for the organization [6].

For organizations to grow and last over a long term it is necessary to find current trends and opportunities. Strategic alignment represents organization's behavior, culture and ethics [7]. Strategic alignment ensures that both IT and business strategies are in harmony and IT provides support to business strategy [8]. The concept of strategic alignment was introduced many years ago but enterprise managers yet strive to achieve alignment between business and IT strategies. In organizations for 30 years IT managers have given high consideration to business-IT strategic alignment [9]. However it is significant to understand the business value of IT in achieving goals of a business [10]. It is to be noted that the context of business influences both IT value and the process of the method where both IT and business environment interact each other [11]. In order to establish a business-IT alignment there is a need to deal with the stakeholders who may have diverse aims and objectives that in turn affect the alignment [12]. The structure of IT functions should be flexible in order to increase strategic alignment in organizations [13]. A strategic alignment model (SAM) used strategic fit and strategic integration as two fundamental dimensions which are defined by four domains [14]. A business-IT alignment is a co-evolutionary process and a model was presented based on co-evolution theory [15]. Organizations adopt latest technologies as they emerge but this may not be useful unless business strategies are aligned with IT strategies; in other words business and IT strategies should co-evolve in order to avail optimum benefits of either strategy [16]. Co-evolution causes to increase performance and efficiency in business processes and in view of changing market customers requirements are also fulfilled [17].

In the co-evolutionary framework under study a monitoring mechanism has been setup that checks any change in business or IT. As soon as any change occurs the 'K-mediator' informs to the respective entity to co-evolve and hence co-evolution occurs. A 'K-mediator' framework was developed by [18] which is knowledgeable in both business and IT and it plays a central role in the co-evolutionary framework.

\section{Material and Method}

The co-evolutionary framework which has been selected is comprised of three levels in business and information technology with respective components such as strategy, rules, software, hardware etc. All the levels with the respective components are integrated by K-mediator that facilitates co-evolution. Fig. 1 shows the three levels (strategic, operational and individual) with k-mediator in the co-evolutionary framework.

\subsection{Strategic Layer}

Companies like to be competitive in the marketplace and, therefore, business strategies need to be 
changed. As soon as the business strategies are changed IT strategies must be changed in order to support the business strategies. Since the k-mediator is knowledgeable in both business and IT this co-evolution can occur in both business and IT.

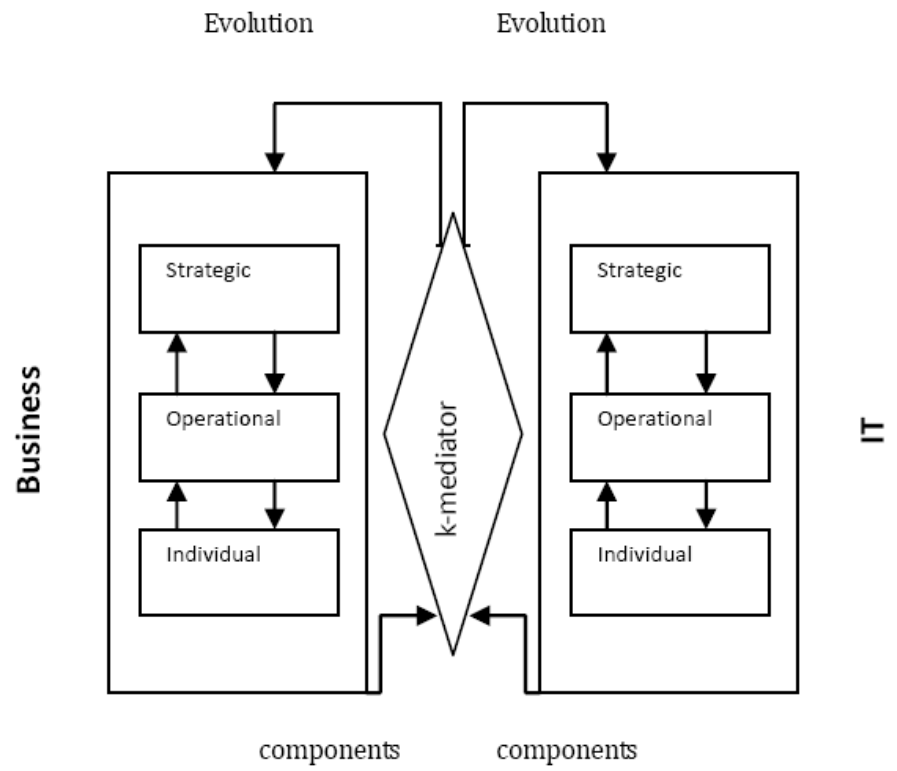

Fig. 1. Co-evolutionary framework.

\subsection{Operational Layer}

At this level business processes and underlying technologies support each other which can happen only when business executives and IT personnel discuss their requirements with each other. Business objectives can only be achieved when operational performance is optimum in result of mutual collaboration between business and IT.

\subsection{Operational Layer}

An IT architecture must fulfil the individual's requirements and since business requirements change rapidly users involvement is essential in the development process.

In order to determine effectiveness of the co-evolutionary framework it was decided to collect data using survey instrument. In order to obtain quantitative scale and qualitative data a useful questionnaire approach was used [19]. It was also ensured a person in each company was knowledgeable in both business strategies, processes and IT strategies and implementation to operate as k-mediator. The survey instrument was prepared in three categories i.e. business strategy, IT strategy and performance. The survey instrument was delivered to almost 45 organizations in different sectors and 26 organizations returned the instruments. The survey questionnaires were scrutinized and sorted out 24 questionnaires were found complete in all aspects. After a reliability test it was found 21 questionnaires had Cronbach's alpha value greater than 0.7 that gave confidence to select them for the study. Table 1 shows the type of organizations were contacted and the number of surveys selected to carry out this study.

Table 1. Organizations Types and Number of Surveys

\begin{tabular}{lccc}
\hline \hline Type of organization contacted & $\begin{array}{c}\text { No. of organizations } \\
\text { contacted }\end{array}$ & $\begin{array}{c}\text { Percentage of Surveys } \\
\text { received }\end{array}$ & $\begin{array}{c}\text { No. of selected } \\
\text { surveys }\end{array}$ \\
\hline Manufacturing & 17 & 47 & 6 \\
\hline Financial institutions & 20 & 65 & 12 \\
\hline Other & 8 & 62 & 3 \\
\hline \hline
\end{tabular}

According to the framework co-evolution should occur in a company when a new business strategy is 
adopted to meet a business requirement and essentially IT strategy needs to be changed consequently performance of the business will be improved. In order to determine performance with the companies Table 2 depicts the performance parameters that have been used in the survey instrument:

Table 2. Parameters for Organization Performance

\begin{tabular}{l|l}
\hline \hline Parameter & Description \\
\hline $\mathrm{QP}$ & Improvement in quality of the product or service \\
\hline $\mathrm{CS}$ & Increase in level of customer satisfaction \\
\hline $\mathrm{OM}$ & Improvement in organization image \\
\hline $\mathrm{RI}$ & Impact in return on investment \\
\hline $\mathrm{AG}$ & Increase in annual growth \\
\hline \hline
\end{tabular}

There are many factors that may affect the business-IT alignment [20] but we are interested in strategies adopted in both business and IT domains and their effectiveness in the organizations under study. Table 3 and Table 4 show the parameters for business strategies and IT strategies used in the survey instrument:

Table 3. Business Strategies Used in the Survey

\begin{tabular}{ll}
\hline \hline Business strategy & Description \\
\hline BIT & Impact of IT in business process \\
\hline BPR & Business process reengineering \\
\hline BIN & Involvement of IT people in business \\
\hline BGR & Growth in business products \\
\hline BRK & Willingness to take risks \\
\hline \hline
\end{tabular}

Table 4. IT Strategies Used in the Survey

\begin{tabular}{l|l}
\hline \hline IT strategy & Description \\
\hline ITB & Business knowledge in IT plan \\
\hline ITA & Acquirement of IT \\
\hline ITU & Updating IT for business requirement \\
\hline ITC & Cost involve in IT acquisition \\
\hline ITE & High level of expertise in IT \\
\hline \hline
\end{tabular}

\section{Results and Discussions}

It was observed the consistency in data received from different organizations implying the co-evolutionary framework has been successful in achieving its objectives. In order to collect data in the survey instrument Likert's scale was used with values ranging from 1 to 5 where 1 stands for 'Strongly Disagree' (SDA) and 5 stands for 'Strongly Agree' (SA). The remaining values in between are as $2=$ 'Disagree' (DA), 3='Neutral' (NU) and 4='Agree' (AG). Table 5 shows the responses that the respondents from different organizations have given in the questionnaires. The data depicts the values for the parameters of organization performance, business strategy and IT strategy with the respective average scores.

It is observed that there has been an impact of co-evolution in return on investment in organizations (PRI). The data shows employees of the organizations have agreed the performance is increased in terms of annual growth (PAG). This is achieved due to IT that has been inducted in expediting business processes and involvement of IT personnel in developing business strategies (BIT and BIN). It clearly indicates the business executives discuss business strategies with IT planners in order to implement their strategies successfully. In other words business requirements are supported by technologies simultaneously which result co-evolution in business and IT. The data is also evident that organizations have updated existing technologies in order to meet business requirements (ITU). Since the IS organizations are using technologies in consultations with business executives the quality of products and services is also increasing (PQP) consequently the level of customers satisfaction is also increased (PCS). We found that despite lack of highly skilled and experienced 
staff (ITE) organizations were willing to take risks (BRK) in adopting IT during changes in business requirements.

Table 5. Responses and Average Scores

\begin{tabular}{|c|c|c|c|c|c|c|c|}
\hline \multirow{6}{*}{ 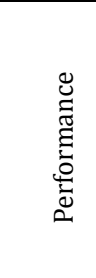 } & Parameter & $\mathrm{SA}=5$ & $\mathrm{AG}=4$ & $\mathrm{NU}=3$ & $\mathrm{DA}=2$ & $\mathrm{SDA}=1$ & Average Score \\
\hline & $\mathrm{QP}$ & 30 & 32 & 9 & 6 & 1 & 3.61 \\
\hline & $\mathrm{CS}$ & 20 & 36 & 12 & 4 & 2 & 3.52 \\
\hline & $\mathrm{OM}$ & 20 & 28 & 6 & 12 & 2 & 3.23 \\
\hline & RI & 35 & 40 & 0 & 6 & 1 & 3.90 \\
\hline & AG & 30 & 36 & 3 & 8 & 1 & 3.71 \\
\hline \multirow{5}{*}{ 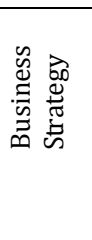 } & BIT & 45 & 40 & 0 & 4 & 0 & 4.23 \\
\hline & BPR & 25 & 32 & 6 & 8 & 2 & 3.47 \\
\hline & BIN & 45 & 40 & 0 & 4 & 0 & 4.23 \\
\hline & BGR & 35 & 32 & 6 & 6 & 1 & 3.80 \\
\hline & BRK & 25 & 28 & 9 & 8 & 2 & 3.42 \\
\hline \multirow{5}{*}{ 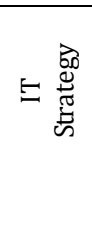 } & ITB & 40 & 40 & 0 & 6 & 0 & 4.09 \\
\hline & ITA & 20 & 24 & 3 & 14 & 3 & 3.04 \\
\hline & ITU & 45 & 36 & 0 & 6 & 0 & 4.14 \\
\hline & ITC & 25 & 28 & 6 & 8 & 3 & 3.33 \\
\hline & ITE & 15 & 20 & 9 & 16 & 2 & 2.95 \\
\hline
\end{tabular}

\section{Conclusion}

In this study we have proved that the co-evolution framework has been useful in business growth and successful to bring both business and IT in alignment in SMEs. Since technologies and business strategies are changing so rapidly a complete alignment is almost impossible due to available resources within organizations. We conclude that if all organizations use the co-evolutionary framework that could help increase in revenue, growth in business and customer satisfaction.

\section{References}

[1] Silvius, A. (2009). Business and IT alignment: What we know and what we don't know. Proceedings of International Conference on Information Management and Engineering (pp. 558-563).

[2] Khan, M. A. (2013). An integrated framework to bridging the gap between business and information technology - A Co-evolutionary approach. Canadian Journal of Pure and Applied Sciences, 7, 2611-2618.

[3] Pearlson, K., \& Saunders, C. (2010). Managing and Using Information Systems: A Strategic Approach (4th ed.) Wiley.

[4] Reich, H., \& Benbasat, I. (2000). Factors that Influence the social dimension of alignment between business and information technology objectives. MIS Quarterly, 24, 81-113.

[5] Zedan, H., Zhou, S., Sampat, N., Chen, X., Cau, A., \& Yang, H. (2001). K-Mediator: Towards evolving information systems. Proceedings of IEEE International Conference on Software Maintenance (pp. 520-527).

[6] Yujie, N., \& Xindi, W. (2011). Research on the matching of IT strategic planning and business strategy. Proceedings of International Conference on Computer Science and Information Technology: Vol. 6 (pp. 177-181).

[7] Winzker, W., \& Pretorius, L. (2015). Keys to innovation: System thinking, strategic alignment, technology focus. Proceedings of PICMET '15 Conference: Management of the Technology (pp. 632-642). USA. 
[8] Mckeen, J. D., \& Smith, H. (2003). Making IT happen: Critical issues in IT management, Chichester; Wiley.

[9] Kappelman, L., McLean, E., Luftman, J., \& Johnson, V. (2013). Key issues of IT organizations and their leadership: The 2013 SIM IT trends study. MIS Quarterly Executive, 12, 227-240

[10] Lee, C. S. (2001). Modeling the business value of information technology. Information and Management, 39, 191-210.

[11] Yao, L. J., Liu, C., \& Chan, S. H. (2010). The influence of firm specific context on realizing information technology business value in manufacturing industry. International Journal of Accounting Information Systems, 11, 353-362.

[12] Alaeddini, M., \& Salekfard, S. (2013). Investigating the role of an enterprise architecture project in a business-IT alignment in Iran. Information Systems Frontier, 15, 67-88.

[13] Huang, L. (2009). The contingent role of innovation between IT management sophistication and strategic alignment. Journal of Global Information Management, 17, 60-92.

[14] Chuan, P., Qing, Y., Michael, T., \& Hsing, C. (2012). Examining the effect of the strategic alignment of business planning and information systems planning in China. Advances in information Sciences and Service Sciences (AISS), 4, 561-570.

[15] Benbya, H., \& McKelvey, B. (2006). Using coevolutionary and complexity theories to improve IS Alignment: A multi-level approach. Journal of Information Technology, 21, 284-298

[16] Khan, M. A., \& Zedan, H. (2010). Alignment strategies and frameworks in co-evolution of business and information technology. Proceedings of International Conference on Information, Networking and Automation. VI-133-136, China.

[17] Khan, M. A. (2016). Understanding a Co-evolution Model of Business and IT for Dynamic Business Processes Requirements. International Journal of Advanced Computer Science and Applications, 7, 348-352

[18] Zedan, H., Zhou, S., Sampat, N., Chen, X., Cau, A., \& Yang, H. (2001). K-Mediator: Towards Evolving Information Systems. Proceedings of IEEE International Conference on Software Maintenance (pp. 520-527).

[19] Cronford, T., \& Smithson, S. (1997). Project Research in Information Systems: As Student's Guide. London Macmillan Press.

[20] Khan, M. A. (2012). Analysis of organizational factors that impact the gap between business and information technology - an empirical study. European Journal of Scientific Research, 68, 154-160.

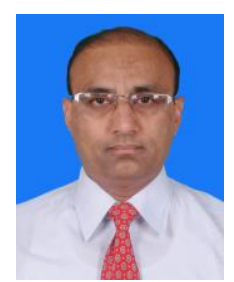

Muhammad Asif Khan received his PhD degree in information systems engineering from De Montfort University, UK. His research areas include information systems architecture, security, management and evaluation of information systems. He has published many research papers in reputed journals and conferences. He has taught in various higher education institutions at graduate and under graduate levels. Currently he is working as an Assistant Professor in the Department of Information Systems at College of Computer Science and Engineering at Taibah University, Saudi Arabia.

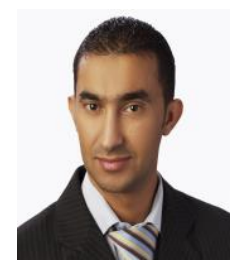

Essa Abdullah Hezzam received his $\mathrm{PhD}$ degree in computer information system from AABFS University, Jordan. His research areas include enterprise architecture, temporal database and design, software engineering, and web applications. He has taught in various higher education institutions at graduate and under graduate levels. Currently he is working as an Assistant Professor in the Department of Information Systems at College of Computer Science and Engineering, Taibah University, Saudi Arabia. 